\title{
Study of Methane Aromatization over \\ Mo-Containing Zeolite Catalysts with \\ a Hierarchical Pore System
}

\author{
Lyudmila L. Korobitsyna*a, Konstantin N. Zharnov ${ }^{\text {, }}$ \\ Andrey A. Stepanov and Alexander V. Vosmerikov ${ }^{\mathrm{a}, \mathrm{b}}$ \\ anstitute of Petroleum Chemistry SB RAS \\ 4 Akademichesky, Tomsk, 634055, Russia \\ ${ }^{b}$ National Research Tomsk State University \\ 36 Lenin, Tomsk, 634050, Russia
}

Received 19.12.2018, received in revised form 14.01.2019, accepted 10.02.2019

\begin{abstract}
Physicochemical and catalytic properties of $4.0 \%$ Mo/ZSM-5 catalysts manufactured on the basis of zeolites with a hierarchical pore system are investigated. The effect of the conditions of synthesis of zeolites with an additional mesoporous structure on their textural and acidic characteristics is studied. The structure and morphology of crystals of synthesized zeolites and catalysts produced from them are determined by the methods of X-ray diffraction analysis and high-resolution scanning transmission electron microscopy. It is shown that 4.0\% Mo/ZSM-5 catalysts produced from zeolites with a mesoporous structure exhibit higher activity and stability in the course of methane dehydroaromatization.
\end{abstract}

Keyword: methane, dehydroaromatization, zeolite catalysts, mesopores, carbon black.

Citation: Korobitsyna L.L., Zharnov K.N., Stepanov A.A., Vosmerikov A.V. Study of methane aromatization over Mo-containing zeolite catalysts with a hierarchical pore system, J. Sib. Fed. Univ. Chem., 2019, 12(1), 118-125. DOI: $10.17516 / 1998-2836-0111$

\footnotetext{
(C) Siberian Federal University. All rights reserved

* Corresponding author E-mail address: kll@ipc.tsc.ru
} 


\title{
Исследование процесса дегидроароматизации метана \\ на Мо-содержащих цеолитных катализаторах \\ с иерархической системой пор
}

\author{
Л.Л. Коробицына ${ }^{a}$, К.Н. Жарнов ${ }^{\sigma}$, \\ А.А. Степанов ${ }^{\text {a }}$ А.В. Восмериков ${ }^{\mathrm{a}, \boldsymbol{\sigma}}$ \\ ${ }^{a}$ Институт химии нефти СО РАН \\ Россия, 634055, Томск, пр. Академический, 4 \\ ${ }^{6}$ Национальный исследовательский \\ Томский государственнылй университет \\ Россия, 634050, Томск, пр. Ленина, 36
}

Исследованы физико-химические и каталитические свойства контактов 4,0 \% Mo/ZSM-5, полученных на основе цеолитов с иерархической системой пор. Изучено влияние условий синтеза цеолитов с дополнительной мезопористой структурой на их текстурные и кислотные характеристики. Методами рентгеноструктурного анализа и сканирующей электронной микроскопии установлена структура и морфология кристаллов синтезированных цеолитов и катализаторов, полученных на их основе. Показано, что катализаторы 4,0 \% Mo/ZSM-5, полученные на основе иеолитов с мезопористой структурой, проявляют более высокую активность и стабильность в проиессе дегидроароматизации метана.

Ключевые слова: метан, дегидроароматизацчия, цุеолитные катализаторы, мезопоры, технический углерод.

\section{Введение}

Рациональное использование природного и попутных нефтяных газов, основным компонентом которых является метан, имеет большое значение с точки зрения как получения ценных продуктов нефтехимии, так и решения экологических проблем. Известно, что наибольшую активность и селективность в процессе дегидроароматизации метана проявляют Мо-содержащие цеолиты типа ZSM-5 [1-3]. Структура цеолита, используемого в качестве носителя для приготовления Mo/ZSM-5 катализаторов, оказывает существенное влияние на эффективность их работы в данном процессе. Одним из недостатков таких катализаторов считается быстрая потеря активности в результате зауглероживания их поверхности. Наличие вторичной мезопористой структуры в цеолитной матрице будет способствовать диффузии активного металлического компонента в поры цеолита и улучшению выхода образующихся ароматических соединений из объема на поверхность катализатора, что приведет к повышению его активности и стабильности работы в процессе дегидроароматизации метана $[4,5]$.

Цель настоящей работы - получение Mo/ZSM-5 катализаторов на основе цеолитов с дополнительной мезопористой структурой, исследование их физико-химических и каталитических свойств в процессе дегидроароматизации метана. 


\section{Экспериментальная часть}

Цеолиты с мезопористой структурой получали методом гидротермального синтеза из щелочных алюмокремнегелей с мольным соотношением $15 \mathrm{Na}_{2} \mathrm{O}: 5,4 \mathrm{R}: \mathrm{Al}_{2} \mathrm{O}_{3}: 40 \mathrm{SiO}_{2}: 2200 \mathrm{H}_{2} \mathrm{O}$, где $\mathrm{R}$ - гексаметилендиамин. К полученному гелю на стадии синтеза добавляли высокодисперсный порошок технического углерода марки П354 (производитель Институт проблем переработки углеводородов СО РАН, г. Омск), содержание которого варьировалось от 0,5 до 5,0 \% мас. Суспензию перемешивали в течение 0,5 ч, помещали в автоклав и проводили синтез при температуре $170-175{ }^{\circ} \mathrm{C}$ в течение 4 сут. Твердую фазу отфильтровывали на воронке Бюхнера, промывали дистиллированной водой до $\mathrm{pH}=6-7$ и высушивали при температуре $100{ }^{\circ} \mathrm{C}$ в сушильном шкафу в течение 4 ч. Для удаления темплата и технического углерода полученный продукт прокаливали на воздухе при температуре $550-560{ }^{\circ} \mathrm{C}$ в течение 6 ч. Для перевода цеолита из натриевой в аммонийную форму проводили его декатионирование 25\%-м водным раствором $\mathrm{NH}_{4} \mathrm{Cl}$ при температуре $90{ }^{\circ} \mathrm{C}$ в течение 2 ч. Приготовленные образцы обозначены как К1 - исходный цеолит, полученный без углерода; К2, К3, К4, К5 и К6 - цеолиты, полученные при добавлении 0,$5 ; 1,0 ; 2,0 ; 3,5$ и 5,0 \% углерода соответственно.

Качество синтезированных цеолитов контролировали с помощью методов ИКспектроскопии и рентгенофазового анализа. ИК-спектры образцов снимали на ИК-Фурье спектрометре «Nicolet 5700» в области 2000-400 см-1. Степень кристалличности цеолитов определяли методом ИК-спектроскопии по методике, описанной в работе [6]. Рентгенофазовый анализ проводили на дифрактометре DISCOVER D8 (Bruker) в диапазоне углов $2 \vartheta=10-70$ градусов. Оценку параметров пористой структуры и определение удельной поверхности образцов осуществляли на автоматизированном газоадсорбционном анализаторе TriStar 3020 («Micromeritics», США). Удельная поверхность рассчитывалась по изотерме низкотемпературной сорбции паров азота (метод БЭТ). Электронно-микроскопические исследования морфологии кристаллов цеолитов проводили с использованием растрового электронного сканирующего микроскопа LEO-1420. Кислотные свойства образцов исследовали методом термопрограммированной десорбции (ТПД) аммиака, позволяющим установить распределение кислотных центров по силе и их концентрацию.

Катализаторы 4,0 \% Mo/ZSM-5 готовили методом сухого механического смешения цеолитов в $\mathrm{NH}_{4}$-форме, синтезированных с различным количеством техническим углерода, с наноразмерным порошком Мо, полученным методом электрического взрыва проводника в среде аргона [7]. Затем порошковые смеси прокаливали в муфельной печи при температуре $540{ }^{\circ} \mathrm{C}$ в течение 4 ч.

Процесс неокислительной конверсии метана (степень чистоты 99,99 \% об.) проводили в установке проточного типа с неподвижным слоем катализатора при температуре $750{ }^{\circ} \mathrm{C}$, атмосферном давлении и объемной скорости подачи метана 1000 ч$^{-1}$. Объем загружаемого в трубчатый кварцевый реактор катализатора составлял 1,0 см³, размер его гранул - 0,5-1,0 мм. Перед началом реакции катализатор нагревали в токе гелия до $750{ }^{\circ} \mathrm{C}$, выдерживали при этой температуре в течение 10 мин, после чего прекращали подачу гелия и начинали подавать метан. Продукты реакции через каждые 40 мин работы катализатора анализировали методом ГЖХ с использованием хроматографа «Хроматэк-Кристалл 5000.2». Для оценки каталитической ак- 
тивности образцов определяли степень превращения метана и выход образующихся продуктов реакции.

\section{Результаты и обсуждение}

На рис. 1 приведены ИК-спектры и рентгенограммы цеолитов, синтезированных без использования и с добавкой технического углерода в количестве 1,0 и 3,5 \%. Из представленных данных видно, что использование при синтезе цеолита технического углерода не влияет на его структурные свойства. Все полученные цеолиты относятся к типу ZSM-5, а их степень кристалличности составляет $100 \%$.

На рис. 2 даны электронно-микроскопические снимки цеолита, синтезированного без использования (рис. $2 a$ ) и с добавкой технического углерода (рис. 26 и в). Частицы исходного цеолита К1 довольно однородны по своему составу и имеют вид поликристаллических сфероидов с размерами от 6 до 8 мкм. На микроснимке цеолита, синтезированного с добавлением 1,0\% углерода, после прокаливания при $540^{\circ} \mathrm{C}$ наблюдается более рыхлое соединение (сочленение) кристаллов в поликристаллических сфероидах, при этом их размеры изменяются в более широком интервале - от 4 до 8 мкм (рис. 2б). При увеличении количества углерода в процессе синтеза цеолита до 3,5 \% и последующем прокаливании кристаллы цеолита становятся еще более неоднородными (рис. 26). Размер поликристаллических сфероидов изменяется от 4 до 9 мкм, кроме того происходит образование более крупных частиц с размером до 12 мкм, морфология многих из которых отличается от строения частиц исходного цеолита К1.

Значения площади удельной поверхности, площади и объема микропор, а также суммарного объема пор образцов, полученных на основе цеолитов, синтезированных с различным содержанием технического углерода, представлены в табл. 1. Наибольшая площадь удельной поверхности наблюдается у исходного цеолита К1 и составляет 398 м²/г. При увеличении концентрации технического углерода, используемого при синтезе цеолита, от 0,5 до 5,0 \% происходит снижение площади удельной поверхности и рост объема мезопор от 0,02 до $0,08 \mathrm{~cm}^{3} / \Gamma$. При этом объем микропор изменяется незначительно - от 0,15 до 0,18 см³/г.

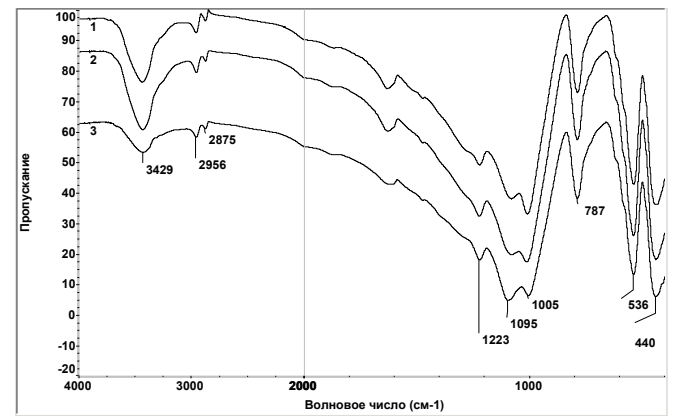

$\mathrm{a} / \mathrm{a}$

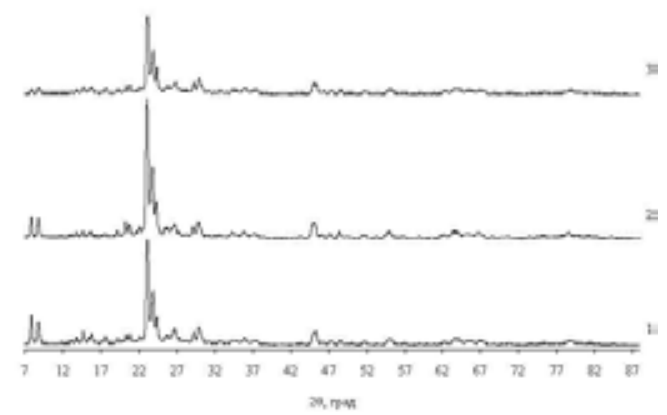

б/b

Рис. 1. ИК-спектры (а) и рентгенограммы (б) цеолитов, синтезированных без и с использованием различного количества технического углерода: $1-0 \%, 2-1,0 \%$ и $3-3,5 \%$

Fig. 1. IR-spectra (a) and XRD patterns (b) of zeolites synthesized without the use of carbon black and with the use of various carbon amounts: $1-0 \%, 2-1,0 \%, 3-3,5 \%$ 


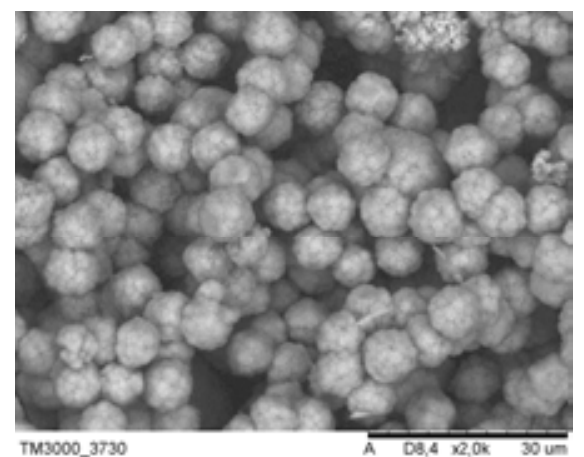

$\mathrm{a} / \mathrm{a}$

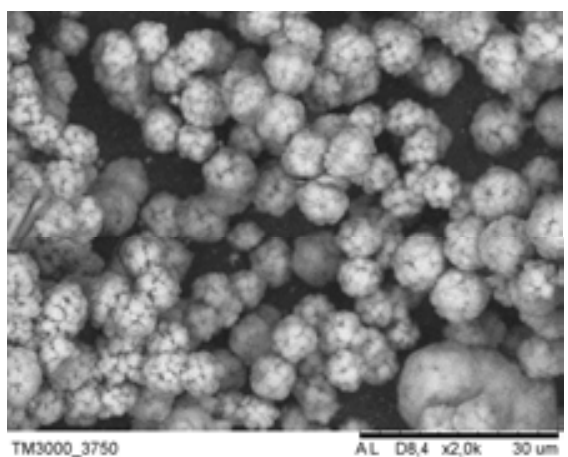

б/b

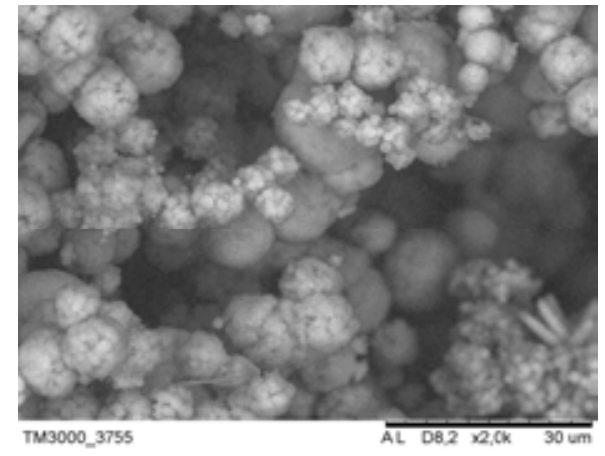

$\mathrm{B} / \mathrm{C}$

Рис. 2. Электронно-микроскопические снимки цеолитов, синтезированных без (а) и с использованием различного количества технического углерода 1,0 \% (б) и 3,5 \% (в)

Fig. 2. Electron micrographs of zeolites synthesized without the use of carbon black (a) and with the use of carbon black amounts of $1,0 \%(b)$ and $3,5 \%$ (c)

Таблица 1. Характеристика удельной поверхности и пористой структуры цеолитов

Table 1. Surface properties of zeolites

\begin{tabular}{|c|c|c|c|c|c|}
\hline Образец & $\begin{array}{c}\mathrm{S}_{\text {уд. }}(\mathrm{BET}), \\
\mathrm{M}^{2} / \Gamma\end{array}$ & $\begin{array}{c}\mathrm{S}_{\text {уд. }} \\
\text { (микропоры), } \\
\mathbf{M}^{2} / \Gamma\end{array}$ & $\begin{array}{c}\text { Суммарный } \\
\text { объем пор, } \\
\mathrm{cm}^{3} / \Gamma\end{array}$ & $\begin{array}{c}\text { Объем } \\
\text { микропор, } \\
\mathrm{cm}^{3} / \Gamma\end{array}$ & $\begin{array}{c}\text { Объем } \\
\text { мезопор, } \\
\mathrm{cm}^{3} / \Gamma\end{array}$ \\
\hline $\mathrm{K} 1$ & 398 & 322 & 0,20 & 0,18 & 0,02 \\
\hline К3 & 379 & 301 & 0,21 & 0,15 & 0,06 \\
\hline К4 & 378 & 299 & 0,22 & 0,16 & 0,06 \\
\hline К5 & 375 & 290 & 0,24 & 0,17 & 0,07 \\
\hline K6 & 373 & 279 & 0,26 & 0,18 & 0,08 \\
\hline
\end{tabular}

Исследования кислотных свойств исходного цеолита К1 и цеолитов с мезопористой структурой показали, что на термодесорбционных кривых присутствуют два пика с четко выраженными температурными максимумами, свидетельствующие о наличии двух типов кислотных центров. Из приведенных в табл. 2 данных видно, что сила и концентрация кислотных центров исходного цеолита К1 и мезопористого цеолита К 3 , синтезированного с добавкой 1,0 \% технического углерода, близки. Увеличение содержания углерода в реакцион- 
Таблица 2. Кислотные характеристики цеолитов

Table 2. Acidic characteristics of zeolites

\begin{tabular}{|c|c|c|c|c|c|}
\hline \multirow{2}{*}{ Образец } & \multicolumn{2}{|c|}{ Температура, ${ }^{\circ} \mathrm{C}$} & \multicolumn{3}{|c|}{ Концентрация, мкмоль $Г$} \\
\cline { 2 - 6 } & $\mathrm{T}_{\mathrm{I}}$ & $\mathrm{T}_{\mathrm{II}}$ & $\mathrm{C}_{\mathrm{I}}$ & $\mathrm{C}_{\mathrm{II}}$ & $\mathrm{C}_{\Sigma}$ \\
\hline К1 & 235 & 480 & 753 & 388 & 1141 \\
\hline К3 & 235 & 475 & 767 & 389 & 1156 \\
\hline К4 & 230 & 470 & 617 & 364 & 981 \\
\hline К5 & 235 & 470 & 643 & 368 & 1011 \\
\hline К6 & 245 & 475 & 874 & 372 & 1246 \\
\hline
\end{tabular}

Примечание. $\mathrm{T}_{\mathrm{I}}, \mathrm{T}_{\mathrm{II}}$ - температуры максимумов низко- и высокотемпературных пиков на термодесорбционной кривой; $\mathrm{C}_{\mathrm{I}}, \mathrm{C}_{\mathrm{II}}$ и $\mathrm{C}_{\Sigma}$ - концентрации слабых и сильных кислотных центров и их суммарная концентрация соответственно.

ном геле от 2,0 до 3,5 \% приводит к получению мезопористых цеолитов (К4 и К5) с меньшей концентрацией слабых и сильных кислотных центров. Для образца К6, полученного с использованием 5,0 \% углерода, наблюдается значительное увеличение количества низкотемпературных кислотных центров (до 874 мкмоль/г) и их силы, при этом концентрация сильных кислотных центров изменяется незначительно, а суммарное содержание кислотных центов достигает 1246 мкмоль/г. Таким образом, кислотные свойства цеолитов, как и их текстурные и структурные характеристики, зависят от количества используемого при синтезе цеолитов технического углерода.

Результаты испытаний катализаторов 4,0 \% Mo/ZSM-5, полученных на основе цеолитов, синтезированных с добавкой различного количества углерода, в процессе неокислительной конверсии метана в ароматические углеводороды приведены на рис. $3 a$. Видно, что во всех случаях использование углерода при синтезе цеолитов приводит к повышению активности катализаторов по сравнению с исходным цеолитом К1, полученным без использования углерода. Каталитические свойства цеолитных катализаторов зависят от количества углерода, используемого при синтезе цеолитов, а наибольшую активность и стабильность работы проявляет мезопористый катализатор Мо/КЗ.

Повышение концентрации технического углерода в реакционном алюмокремнегеле, используемом для синтеза цеолита, до 3,5 \% приводит к снижению активности Мо-содержащего цеолитного катализатора, однако его активность выше, чем у катализатора Mo/K1, в течение первых 180 мин реакции, после чего конверсия метана приближается к показателям конверсии для катализатора Mo/K1 и затем сохраняется на одинаковом уровне. Увеличение концентрации добавляемого в процессе синтеза цеолита углерода до 5,0 \% приводит к заметному снижению активности цеолитсодержащего катализатора.

Анализ образующихся в процессе конверсии метана газообразных продуктов показывает, что они состоят в основном из этана и этилена, выход которых возрастает по мере протекания процесса, достигая максимальных значений в интервале времени реакции 220-300 мин (рис. 3б). Затем образование этана и этилена снижается в результате зауглероживания активных центров Мо-содержащих цеолитных катализаторов. Видно, что для мезопористых катализаторов характерно более высокое образование газообразных продуктов, и, по-видимому, 

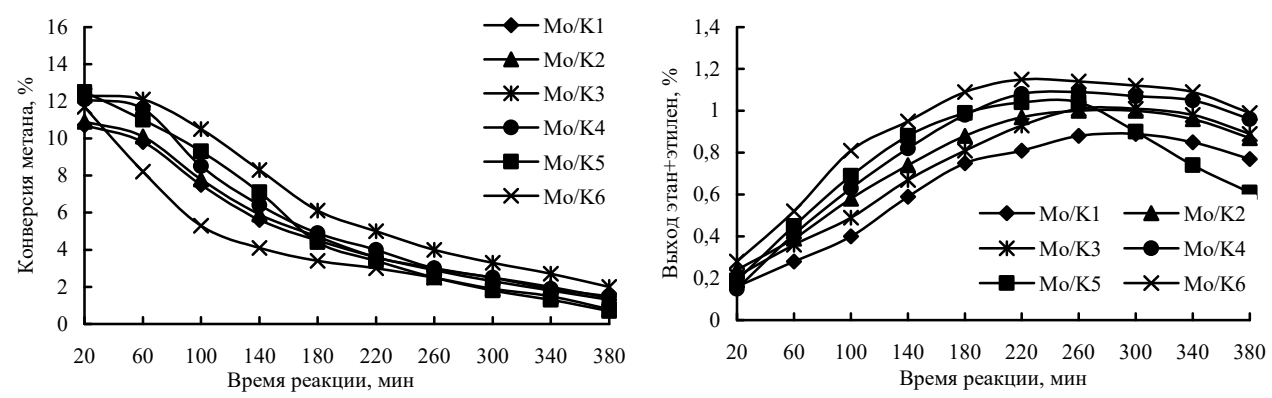

$\mathrm{a} / \mathrm{a}$

$6 / b$
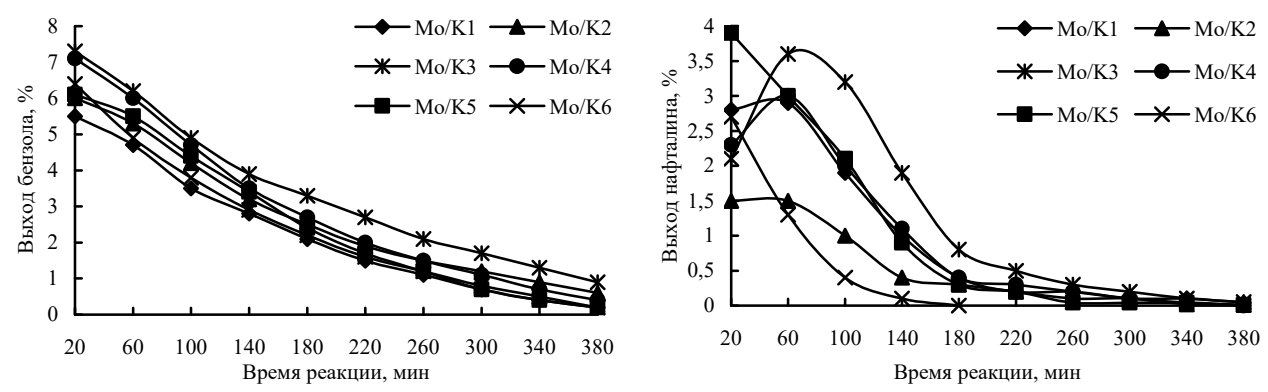

$\mathrm{B} / \mathrm{c}$

$\Gamma / \mathrm{d}$

Рис. 3. Зависимость конверсии метана (а), суммарного выхода этана и этилена (б), выхода бензола (в) и выхода нафталина (г), образующихся на катализаторах Мo/K1; Mo/K2; Mo/K3; Mo/K4; Mo/K5; Mo/K6, от времени реакции

Fig. 3. Time dependence of methane conversion (a), total yield of ethane and ethylene (b), and yield of benzene (c) and naphthalene (d) formed due to the use of Mo/K1, Mo/K2, Mo/K3, Mo/K4, Mo/K5; and Mo/K6 catalysts

это связано с их более высокой крекирующей активностью в данном процессе. Наибольшее количество газообразных продуктов образуется на катализаторе Мo/К6, полученном на основе цеолита, синтезированного с максимальной добавкой технического углерода и содержащего максимальное количество кислотных центров.

В составе жидких продуктов конверсии метана содержатся только ароматические углеводороды, преимущественно бензол и нафталин (рис. 36 , г). Наибольшее количество бензола образуется в первые 20 мин реакции на всех исследуемых катализаторах, после чего его выход постепенно снижается. Увеличение концентрации технического углерода, используемого при синтезе цеолитов, приводит к повышению выхода бензола на катализаторах, полученных на их основе.

Выход нафталина достигает максимальных значений через 20-60 мин реакции, затем его образование снижается (рис. 32). Наиболее резкое падение выхода нафталина наблюдается на катализаторе Мо/К6.

\section{Заключение}

Таким образом, с использованием технического углерода синтезированы высококремнеземные цеолиты типа ZSM-5 с иерархической системой пор. Исследования их физико-химических 
свойств показали, что полученные катализаторы существенно отличаются по текстурным, структурным и кислотным характеристикам, а это приводит к их различиям в каталитических свойствах. Наибольшую активность и стабильность в процессе неокислительной конверсии метана в ароматические углеводороды проявляет мезопористый катализатор, полученный на основе цеолита, при синтезе которого использовался 1,0 \% технического углерода.

\section{Список литературы}

1. Zang C.-L., Li S., Yuan Y., Zhang W.-X., Wu T.H., Lin L.W. Aromatization of methane in the absence of oxygen over Mo-based catalysts supported on different types of zeolites. Catalysis Letters 1998. Vol. 56, P. 207-213.

2. $\mathrm{Xu}$ Y., Lin L. Recent advances in methane dehydro-aromatization over transition metal ionmodified zeolite catalysts under non-oxidative conditions. Applied Catalysis A: General 1999. Vol. 188, P. 53-67.

3. Ma S., Guo X., Zhao L., Scott S., Bao X. Recent progress in methane dehydroaromatization: from laboratory curiosities to promising technology. Journal of Energy Chemistry 2013. Vol. 22, P. 1-20.

4. Schmidt I., Christensen C.H., Hasselriis P., Kustova M.Yu., Brorson M., Dahl S., Johannsen K., Christensen C.H. Mesoporous zeolite single crystals for catalytic hydrocarbon conversion. Studies in Surface Science and Catalysis 2005. Vol. 154, P. 1247-1254.

5. Christensen Ch.H., Johannsen K., Schmid I. Catalytic benzene alkylation over mesoporous zeolite single crystals: improving activity and selectivity with a new family of porous materials. Journal of the American Chemical Society 2003. Vol. 125, P. 13370-13371.

6. Dipak B. Shukla, Viomesh P. Panda J. Estimation of crystalline phase in ZSM-5 zeolites by infrared spectroscopy. Journal of Chemical Technology \& Biotechnology 1989. Vol. 44, P. 147-154.

7. Гусев А.И. Нанокристаллические материалы: методы получения и свойства. Екатеринбург: ИФМ УрО РАН, 1988. 200 c. [Gusev A.I. Nano-crystalline materials: methods of obtaining and properties. Yekaterinburg: IPM UrO RAN, 1998. 200 p. (In Russ.)] 